\title{
Cellular dynamics of growth in sheep and goat synepitheliochorial placentomes: an autoradiographic study
}

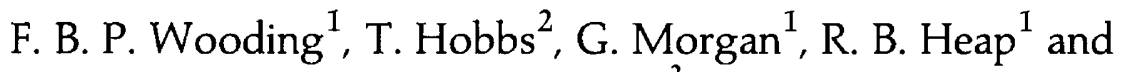 \\ A. P. F. Flint ${ }^{3}$ \\ ${ }^{1} A F R C$ Institute of Animal Physiology and Genetics Research, Babraham, Cambridge CB2 4AT, UK; \\ ${ }^{2}$ Mill Cottage, Fishmarket Street, Thaxted, Essex, UK and ${ }^{3}$ Institute of Zoology, Regent's Park, \\ London NW1 4RY, UK
}

\begin{abstract}
This paper demonstrates that in sheep and goats the two definitive fetomaternal interface layers are developmentally related. The fetal trophectoderm consists of binucleate and uninucleate cells. The apical microvilli of the trophectoderm interdigitate with a layer consisting of syncytial plaques of limited area bounding the maternal connective tissue. Our previous histological ultrastructural and immunocytochemical work has indicated that throughout pregnancy the fetal binucleate cells migrate to and fuse with the uterine epithelium or its derivatives to form these syncytial plaques which constitute a persistent fetomaternal tissue unique to ruminants. This quantitative autoradiographic study of thymidine incorporation into sheep and goat placentas confirms the central role of the binucleate cell in placental growth, demonstrates that throughout pregnancy all binucleate cells migrate and indicates that most of the nuclei of the syncytial plaques, which appear to have a limited lifespan, derive from binucleate cell fusion.
\end{abstract}

\section{Introduction}

Several investigations, both histological (Stegemann, 1974) and gross measurements (Cloete, 1939; Wallace, 1948; Alexander, $1964 \mathrm{a}, \mathrm{b})$ have established that the sheep placentome reaches maximum weight and external dimensions by 90 days of pregnancy ( 55 days before term). The fetal villi and corresponding maternal crypts do not increase in length subsequently but divide repeatedly thus increasing the area of the apposed surface epithelia mediating physiological exchange between mother and fetus. According to Stegemann's careful morphometric study this differentiation is completed by 110-115 days post coitum. She suggested that the considerable subsequent increase in transport across the placenta is then accommodated by an increase in vascularization of the fetal villi and maternal crypts and indentation of fetal blood vessels into the trophectoderm epithelium which increases the efficiency of transport. Unlike the sheep placenta, most of the other placentas investigated morphometrically show an increase in fetomaternal exchange area virtually to term (Baur, 1977) which might be predicted from the continuous and rapid growth of the fetus in this period. Both Baur and Stegemann used similar morphometric techniques so that the results can be legitimately compared, even though recent developments in this field (Mayhew, 1991) indicate that the standard methods do not give accurate absolute values. Our previous studies have demonstrated the central role of the trophectodermal binucleate cells in ruminant implantation and placental growth and their contribution to both trophectodermal growth and the syncytial lining of the maternal caruncular crypts (reviewed by Wooding, 1982; 1992).

Received 2 September 1992.
Preliminary work injecting the fetus in vivo with tritiated thymidine has indicated the quantitative importance of the binucleate cell contribution to placental growth (Wooding et al., 1981). This suggested that all binucleate cells migrate, that most of the nuclei of the caruncular syncytium derive from binucleate cells and that binucleate cell migration occurs throughout pregnancy. The present study confirms and extends these preliminary results in sheep and together with results from a series of experiments in goats indicates that the slowing down of placental differentiation may be much less than suggested by the earlier studies of Alexander $(1964 a, b)$ and Stegemann (1974).

\section{Methods and Materials}

\section{Animals and treatments}

Soay and Clun Forest sheep and Toggenburg goats at various stages of pregnancy (see Tables $I$ and 2 and Fig. 1) from the Institute flocks were used. At known dates after an observed mating the animals were anaesthetized with pentobarbital sodium (Intervet, Cambridge), intubated, and maintained on $\mathrm{NO} / \mathrm{O}_{2}$ before laparotomy. The intact uterus was exteriorized and the fetus was injected transmurally with 0.05 to $0.25 \mathrm{mCi}$ saline containing $0.1-1.0 \mu \mathrm{mol} \mathrm{l}^{-1}$ of tritiated thymidine (Amersham International, UK) into the rump or hindleg identified by gentle manipulation. Transillumination with bright point source light was used to localize the early fetuses. Some animals were injected at a similar site $10 \mathrm{~min}$ after the initial injection with $0.25 \mathrm{ml}$ saline containing $0.5 \mathrm{mg}$ unlabelled thymidine. Three animals were maintained under anaesthesia. Two hours after the 
injection of labelled thymidine, one placentome was surgically removed. The uterus was returned to the abdomen and the animal was allowed to recover. Most animals were not sampled initially but only injected. Other animals used had been ovariectomized or hypophysectomized by methods detailed in Wooding et al. (1986). At the chosen time, more than $\mathrm{I} \mathrm{h}$ after the initial injection (see Tables $I$ and 2), each animal was killed with an overdose of pentobarbital sodium i.v., and the uterus removed. Many other animals between 15 and 150 days pregnant were used only for binucleate cell counting; they were killed and the uterus removed in a similar way. The placenta was then perfused with fixative through the maternal uterine arteries and, after removal of the fetus, via the umbilical vessels as described in Wooding (1980). Fixatives used were $4 \%$ glutaraldehyde (Agar Scientific, Stansted) in phosphate buffer $\left(0.1 \mathrm{~mol} \mathrm{l}^{-1}\right), \mathrm{pH} 7.2$, with $2 \%$ sucrose or $1 \%$ glutaraldehyde $3 \%$ formaldehyde in cacodylate buffer $\left(0.1 \mathrm{~mol} \mathrm{l}^{-1}\right)$, pH 7.2, with $5 \%$ sucrose, both at room temperature. The perfusion was maintained for 20 min; placentomes were divided into matchstick-like pieces (Wooding, 1980) and then immersion fixed for $2 \mathrm{~h}$. Both fixatives gave equivalent results at the light microscope autoradiographic level. Tissue was embedded in glycolmethacrylate (GMA, Agar Scientific) for light microscope autoradiography and araldite for electron microscopy with or without postfixation with osmium (Wooding, 1980). GMA sections $(6 \mu \mathrm{m})$ were cut on a rotary microtome and mounted on glass slides. They were stained with Periodic acid - Schiff's (PAS) reagent, dried, coated by dipping into Ilford K5 photographic emulsion in the dark and stored in the dark for 1-6 months. Development was in Kodak D19 for $5 \mathrm{~min}$ and the silver label was intensified using a silver enhancing solution. Sections were then post-stained with haematoxylin and permanently mounted before counting.

\section{Quantitation of binucleate cells and their migration rate}

The method has been described in detail by Wooding (1983). Briefly, all cells containing nuclei along several strips of trophectoderm selected at random were counted in the electron microscope on sections of phosphotungstic acid stained nonosmicated placentomes. This preparation method selectively enhances nuclei, binucleate cell granules and the microvillar junction and simplifies the recognition of binucleate cells and their migration. When the uninucleate cell count reached one hundred, this constituted one observation. A minimum of four observations were made for at least two placentomes from each placenta. This method of quantitation is not completely unbiased from the standpoint of recent developments in morphometry (Mayhew, 1991). However, the bias is consistent so that the figures are comparable, although not accurate in an absolute sense.

\section{Autoradiographic quantitation}

Glycolmethacrylate sections stained with PAS, developed for autoradiography and finally stained with haematoxylin, clearly displayed nuclei, binucleate cell granules and the microvillar junction. Uninucleate and binucleate trophectodermal cells could readily be identified and easily distinguished from the standard or pyknotic syncytial plaque nuclei. Granulated binucleate cells were immediately obvious; the nuclei of young nongranulated

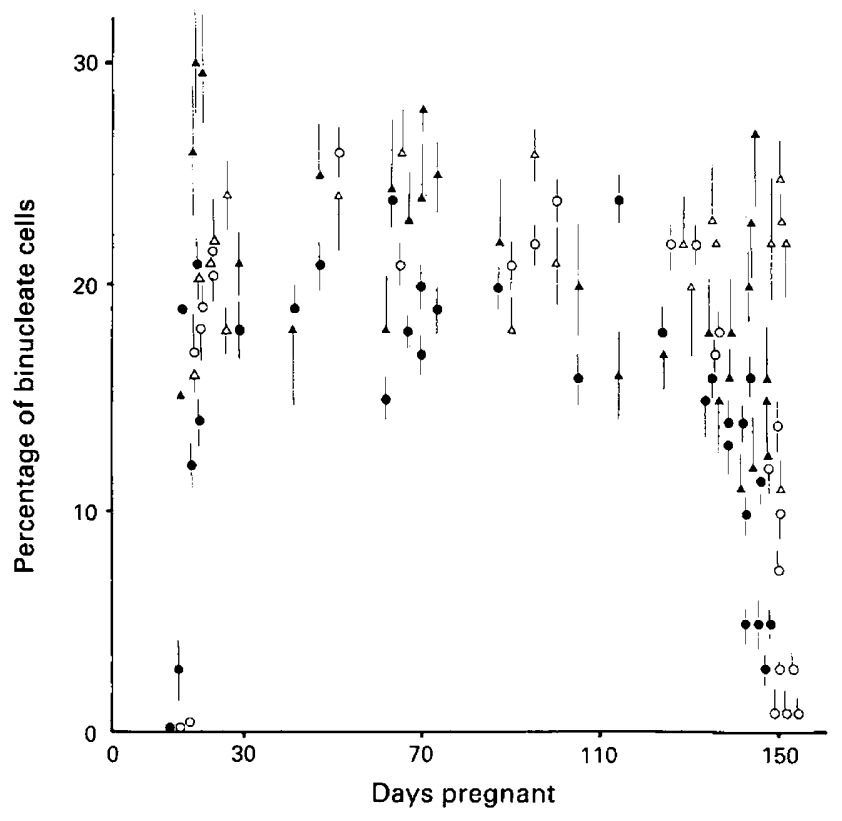

Fig. 1. Percentage of binucleate cells in the predominantly uninucleate trophectodermal epithelium of sheep $(O)$ and goats $(O)$ throughout pregnancy and the percentage of those binucleate cells that are migrating (sheep $(\boldsymbol{\Delta})$; goats $(\Delta)$ ) at any one time. Vertical lines: standard errors of counts.

binucleate cells could usually be recognized by their characteristic stain, which was denser than those of the surrounding uninucleate cells. Nuclei with more than three silver grains were defined as labelled nuclei. All nuclei along randomly selected strips of trophectoderm apposed to syncytium were counted. When one category (uninucleate, binucleate young or granulated, syncytium standard, syncytium pyknotic) reached fifty (50) this constituted one observation. A minimum of ten observations were made on sections from each placenta.

\section{Results}

Quantitation of the number of binucleate cells in the trophectoderm and the percentage of those cells migrating - defined by their participation in the apical tight junction - shows a virtually identical scale and pattern in sheep and goats (Fig. I). Binucleate cell production and migration to form the fetomaternal hybrid syncytium is a constant and quantitatively highly significant process from implantation (16 days post coitum, sheep; 18 days post coitum, goat) virtually to term (145 days post coitum, sheep; 150 days post coitum, goat). The number of binucleate cells observed decreased in the last week of pregnancy, whereas the number of binucleate cells migrating remained above $10 \%$.

The fetal blood capillaries indent the trophectodermal epithelium to an increasing extent from 70-80 days post coitum right up to term. An example of near maximal indentation is shown (Fig. 2a). The distance from the fetal endothelium to the microvillar junction of the trophectoderm is reduced to less than I-2 $\mu \mathrm{m}$ in many places (Fig. 2a), although the overall quantitative significance of this has not yet been morphometrically assessed. 


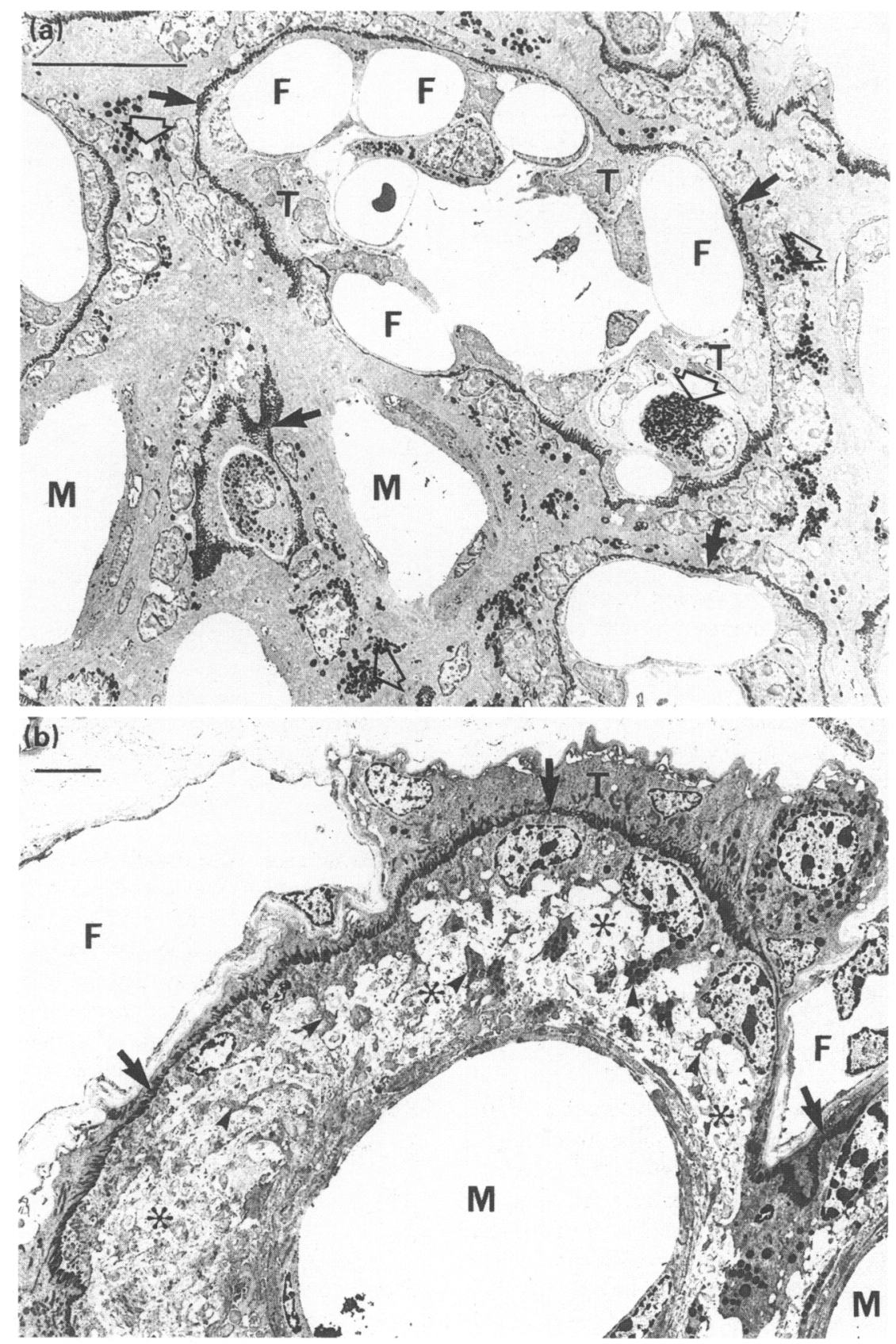

Fig. 2. (a) Electron micrograph from a placentome of a day 128 pregnant sheep perfused with fixative through both fetal (F) and maternal (M) circulations. Note the extreme indentation of the fetal vessels (F) into the trophectodermal epithelium (T). The microvillar junction (closed arrows) and binucleate cell derived granules (open arrow) are highlighted by the phosphotungstic acid stain on the unosmicated araldite section. (b) Electron micrograph from a placentome of a sheep hypophysectomized at day 126 of pregnancy and killed at 166 days. The maternal connective tissue (*) is oedematous and the extensive ramifications of the finely dissected syncytial layer can be clearly seen (arrowheads) around the maternal blood vessel (M). The fetal blood vessels $(F)$ are deeply idented into the trophectodermal epithelium $(T)$ very close to the microvillar junction (arrows). Scale bars $=10 \mu \mathrm{m}$.

The fetomaternal syncytium in sheep and goats presents an increasingly elaborate and finely dissected surface to the maternal connective tissue as pregnancy progresses, increasing its area enormously. This is usually difficult to see since the syncytium invests the maternal vessels so closely, but occasional examples of maternal connective tissue oedema are found where the convoluted ramifications of the basal syncytial surface are clearly shown. The best examples observed were from 


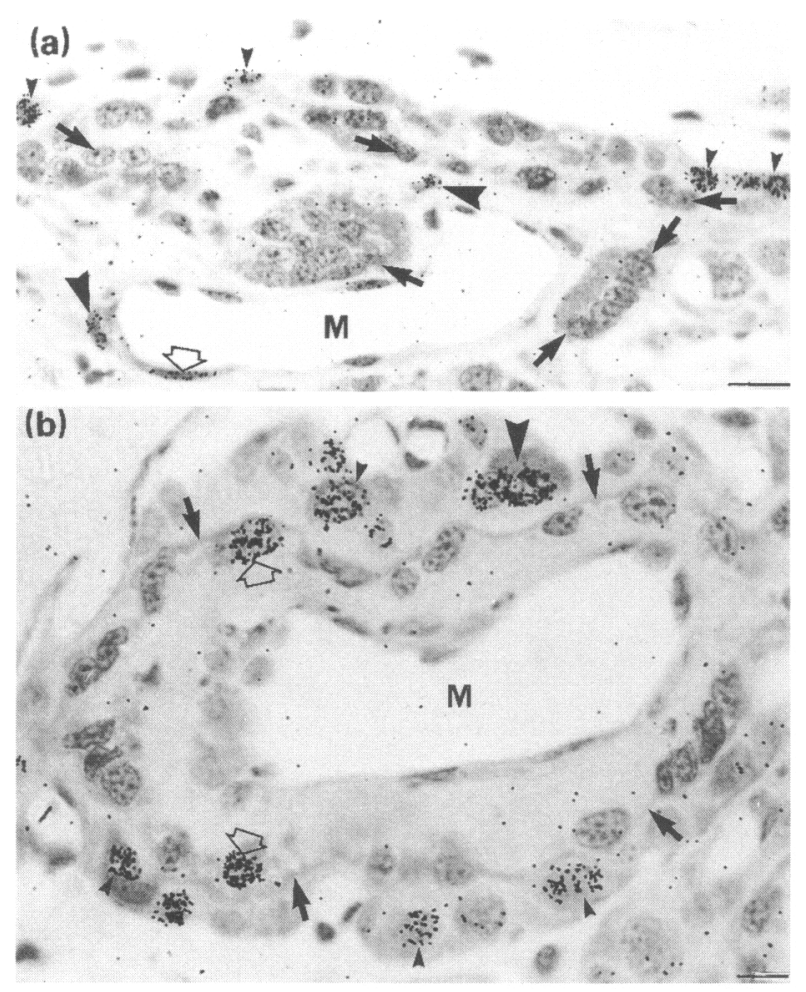

Fig. 3. Light microscope autoradiographs of sections of placentomes from (a) 65 days pregnant and (b) 110 days pregnant goats sampled (a) $1 \mathrm{~h}$ or (b) $48 \mathrm{~h}$ after tritiated thymidine was injected into the fetus. In (a), labelled nuclei are found only in the trophectoderm (small arrowheads), the maternal connective tissue (large arrowheads) and matemal endothelial cells (open arrows). The nuclei in the syncytium (between the arrows) show no significant label. In (b), most of the labelled nuclei are in the trophectoderm (small arrowheads) from which a heavily labelled binucleate cell (large arrowhead) appears to be migrating across the microvillar junction (small arrows) into the syncytium. There are two labelled nuclei in the syncytium (open arrows). M: maternal blood vessels. Scale bars $=10 \mu \mathrm{m}$.

hypophysectomized animals (e.g. Fig. 2b), but specimens in which the maternal circulation is well perfused with fixative show the same effect in places.

Macroscopically there is no obvious preferential accumulation of $\left[{ }^{3} \mathrm{H}\right]$ thymidine derived label at the tips of the fetal villi; at all stages examined, the labelling of trophectodermal nuclei seems evenly distributed along the length of the villi. The nuclei in the syncytial plaques that line the maternal crypts show no label until $36-48 \mathrm{~h}$ after injection, whereas occasional nuclei in maternal connective tissue and endothelial cells label as early as $1 \mathrm{~h}$ after injection (Fig. 3a), but again all of these nuclei show an even distribution of label along the crypt length. The earliest labelling is seen in trophectodermal nuclei, both uninucleate and binucleate cells (Figs 3a; 4a, b). Subsequently the label in the granulated binucleate cell population rises rapidly to a much higher percentage than in the uninucleate or nongranulated binucleate cells (Figs 4a, b; Tables 1 and 2). Cells in the syncytial plaques show no label until the time of peak labelling of binucleate cells. This is also the first time (36-48 $\mathrm{h}$ after injection) that label is observed in migrating cells - the granulated (i.e. mature) binucleate cells which interrupt the microvillar junction between trophectoderm and syncytial plaques (Figs $4 \mathrm{a}$, b;

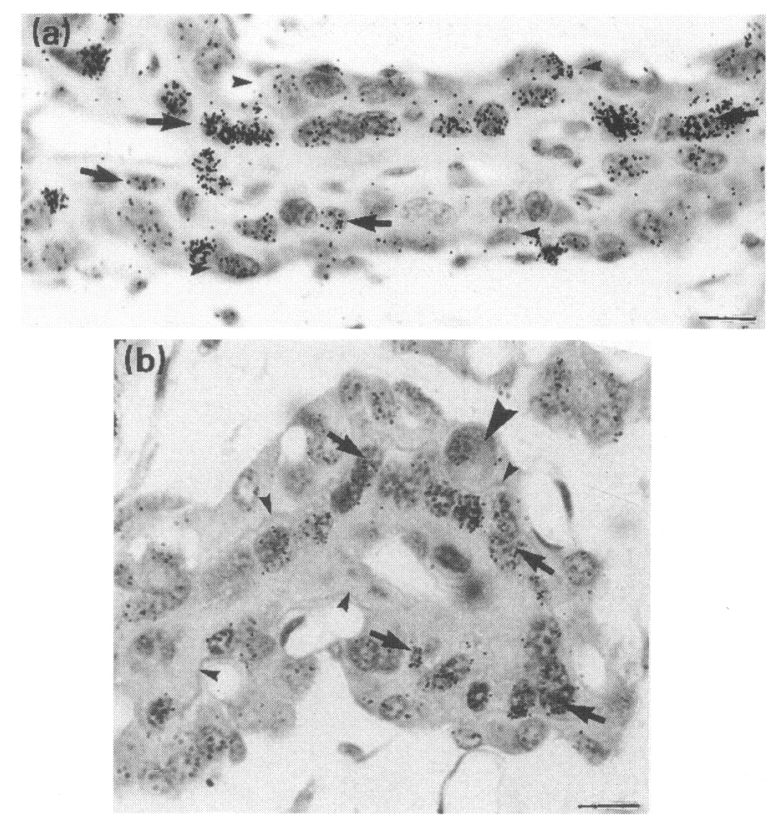

Fig. 4. Light microscope autoradiographs of sections of placentomes from (a) a day 72 pregnant and (b) a day 112 pregnant sheep sampled (a) 7 days or (b) 14 days after a tritiated thymidine was injected into the fetus. In (a), most of the nuclei in the two strips of syncytium (between the arrows) are labelled. Some of the trophectodermal nuclei also show label (between arrowheads). In (b) most of the labelling is restricted to the nuclei in the syncytium (between the arrows). Binucleate cells (large arrowheads) show little label at this stage when migrating across the microvillar junction (small arrowheads). Scale bars $=10 \mu \mathrm{m}$.

$5 \mathrm{a}, \mathrm{b})$. From $48 \mathrm{~h}$ after injection the label in the trophectodermal nuclei falls and the number of labelled nuclei in the syncytium increases (Figs $4 a, b ; 5 a, b$ ). The results in sheep showed that less than $10 \%$ of the nuclei in the syncytium are labelled at $48 \mathrm{~h}$ after injection but gave no indication how early this labelling starts. The experiments in goats demonstrate that no nucleus in the syncytium is labelled before $36 \mathrm{~h}$, coincident with maximum label in the mature granulated binucleate cells (Fig. 4b, Table 2).

In the syncytium two morphological types of nucleus can be clearly identified: 'standard', equivalent in staining density to binucleate cell nuclei, and 'pyknotic' much denser and shrunken by comparison (Fig. 6a, b). There are intermediates between these extremes. There are more standard than pyknotic nuclei but both normally occur in groups. Label incorporation in standard nuclei is seen marginally earlier than label in the pyknotic nuclei; the label in both increases gradually up to seven days after injection. After longer periods the most densely pyknotic nuclei may show more labelling than standard (Figs 7, 8). No highly labelled nuclei remained in either sheep or goat trophectodermal binucleate cells $72 \mathrm{~h}$ or longer after injection.

In one sheep, labelled thymidine was infused into the maternal circulation via the uterine artery and the animal was killed $4 \mathrm{~h}$ after the infusion started. The resulting label was predominantly in the trophectoderm, and there was no label in the nuclei of the syncytial plaques; but a few labelled nuclei were present in fetal and maternal connective tissue and endothelial cells.

The only consistent effect of injecting unlabelled thymidine soon after the tracer was to reduce the percentage of trophectoderm and syncytium nuclear label. 
Table 1. Percentages of labelled placental nuclei after tritiated thymidine injection into the sheep fetus

\begin{tabular}{|c|c|c|c|c|c|c|}
\hline \multirow[b]{2}{*}{$\begin{array}{l}\text { Animal } \\
\text { code }\end{array}$} & \multirow[b]{2}{*}{$\begin{array}{c}\text { Days } \\
\text { pregnant }\end{array}$} & \multirow{2}{*}{$\begin{array}{l}\text { Time after thymidine } \\
\text { injection into fetus } \\
\text { (h) }\end{array}$} & \multicolumn{4}{|c|}{ Percentage of nuclei labelled $( \pm S D)$} \\
\hline & & & Trophectoderm & $\begin{array}{c}\text { Mature } \\
\text { BNC }\end{array}$ & $\begin{array}{l}\text { Syncytium } \\
\text { (standard) }\end{array}$ & $\begin{array}{l}\text { Syncytium } \\
\text { (pyknotic) }\end{array}$ \\
\hline 996 & 118 & 2 & $11 \pm 1$ & 0 & 0 & 0 \\
\hline 998 & 128 & 2 & $12 \pm 1$ & 0 & 0 & 0 \\
\hline 223 & 29 & 3 & $14 \pm 1$ & $2 \pm 2$ & 0 & 0 \\
\hline 984 & 70 & $4^{\mathrm{a}}$ & $21 \pm 2$ & $\overline{0}$ & 0 & 0 \\
\hline 4 & 122 & 17 & $13 \pm 1$ & 0 & $0.3 \pm 0.2$ & 0 \\
\hline 987 & 63 & 18 & $24 \pm 2$ & 0 & $1 \pm 1$ & 0 \\
\hline 849 & 120 & 48 & 18 & 40 & 6 & $2 \pm 1$ \\
\hline 231 & 50 & 50 & $13 \pm 2$ & $19 \pm 4$ & $5 \pm 1$ & $7 \pm 1$ \\
\hline 845 & 70 & 52 & $25 \pm 1$ & $65 \pm 5$ & $10 \pm 2$ & $7 \pm 1$ \\
\hline 852 & 124 & 72 & $16 \pm 1$ & $46 \pm 5$ & $9 \pm 1$ & $5 \pm 1$ \\
\hline 998 & 128 & 98 & $10 \pm 1$ & $7 \pm 1$ & $17 \pm 1$ & $19 \pm 2$ \\
\hline 963 & 66 & 98 & $23 \pm 4$ & $20 \pm 2$ & $24 \pm 1$ & $17 \pm 3$ \\
\hline 996 & 118 & 196 & $8 \pm 1$ & $7 \pm 1$ & $14 \pm I$ & $21 \pm 3$ \\
\hline 5 & 112 & 196 & $5 \pm I$ & $2 \pm I$ & $20 \pm 2$ & $35 \pm 3$ \\
\hline 985 & 58 & 318 & $30 \pm I$ & $14 \pm 2$ & $47 \pm 3$ & $50 \pm 4$ \\
\hline
\end{tabular}

A minimum of three and an average of five counts was made for each value above except for animal 849 where only two counts were possible.

${ }^{2}$ Thymidine infused into the maternal uterine arterial supply.

BNC: binucleate cells.

Table 2. Percentages of labelled placental nuclei after tritiated thymidine injection into the goat fetus

\begin{tabular}{|c|c|c|c|c|c|c|}
\hline \multirow[b]{2}{*}{$\begin{array}{l}\text { Animal } \\
\text { code }\end{array}$} & \multirow[b]{2}{*}{$\begin{array}{c}\text { Days } \\
\text { pregnant }\end{array}$} & \multirow{2}{*}{$\begin{array}{l}\text { Time after thymidine } \\
\text { injection into fetus } \\
\text { (h) }\end{array}$} & \multicolumn{4}{|c|}{ Percentage of nuclei labelled $( \pm S D)$} \\
\hline & & & Trophectoderm & $\begin{array}{c}\text { Mature } \\
\text { BNC }\end{array}$ & $\begin{array}{l}\text { Syncytium } \\
\text { (standard) }\end{array}$ & $\begin{array}{l}\text { Syncytium } \\
\text { (pyknotic) }\end{array}$ \\
\hline 128 & 65 & 1 & $16 \pm 4$ & 0 & 0 & 0 \\
\hline $358^{\mathrm{a}}$ & 120 & 1 & $10 \pm 1$ & 0 & 0.2 & 0.3 \\
\hline 319 & 31 & 3 & $11 \pm 1$ & $2 \pm 1$ & $1 \pm 1$ & $1 \pm 1$ \\
\hline 471 & 116 & 4.5 & $7 \pm 1$ & $1 \pm 1$ & $\overline{0}$ & $\overline{0}$ \\
\hline $342^{\mathrm{a}}$ & 118 & 18 & $15 \pm 1$ & $23 \pm 1$ & 0 & 0 \\
\hline 483 & 118 & 20 & $12 \pm 2$ & $23 \pm 3$ & 0 & 0 \\
\hline 497 & 117 & 28 & $8 \pm 1$ & $44 \pm 5$ & 0 & 0 \\
\hline $343^{\mathrm{a}}$ & 119 & 30 & $11 \pm 1$ & $39 \pm 3$ & 0 & 0 \\
\hline $349^{a}$ & 127 & 35 & $8 \pm 1$ & $46 \pm 3$ & 0 & 0 \\
\hline 492 & 113 & 42 & $12 \pm 2$ & $59 \pm 5$ & $3 \pm 1$ & $1 \pm 1$ \\
\hline 469 & 118 & 44 & $7 \pm 1$ & $52 \pm 3$ & $1 \pm 1$ & $\overline{0}$ \\
\hline 320 & 34 & 48 & $8 \pm 1$ & $28 \pm 3$ & $18 \pm 6$ & $24 \pm 6$ \\
\hline 488 & 123 & 52 & $5 \pm 1$ & $60 \pm 9$ & $4 \pm 1$ & $4 \pm 1$ \\
\hline 478 & 113 & 52 & $8 \pm 1$ & $52 \pm 1$ & $3 \pm 1$ & $2 \pm 1$ \\
\hline $397^{a}$ & 118 & 54 & $8 \pm 1$ & $50 \pm 6$ & $4 \pm 1$ & $4 \pm 1$ \\
\hline 476 & 110 & 72 & $4 \pm 1$ & $15 \pm 1$ & $4 \pm 1$ & $3 \pm 1$ \\
\hline 500 & 115 & 98 & $9 \pm 1$ & $25 \pm 7$ & $12 \pm 2$ & $8 \pm 1$ \\
\hline 472 & 104 & 150 & $4 \pm 1$ & $7 \pm 2$ & $15 \pm 2$ & $8 \pm 2$ \\
\hline 128 & 65 & 150 & $7 \pm 1$ & $6 \pm 1$ & $13 \pm 2$ & $14 \pm 1$ \\
\hline
\end{tabular}

'Ovariectomized animals maintained on medroxyprogesterone acetate.

A minimum of three and an average of five counts was made for each value above.

BNC: binucleate cells. 


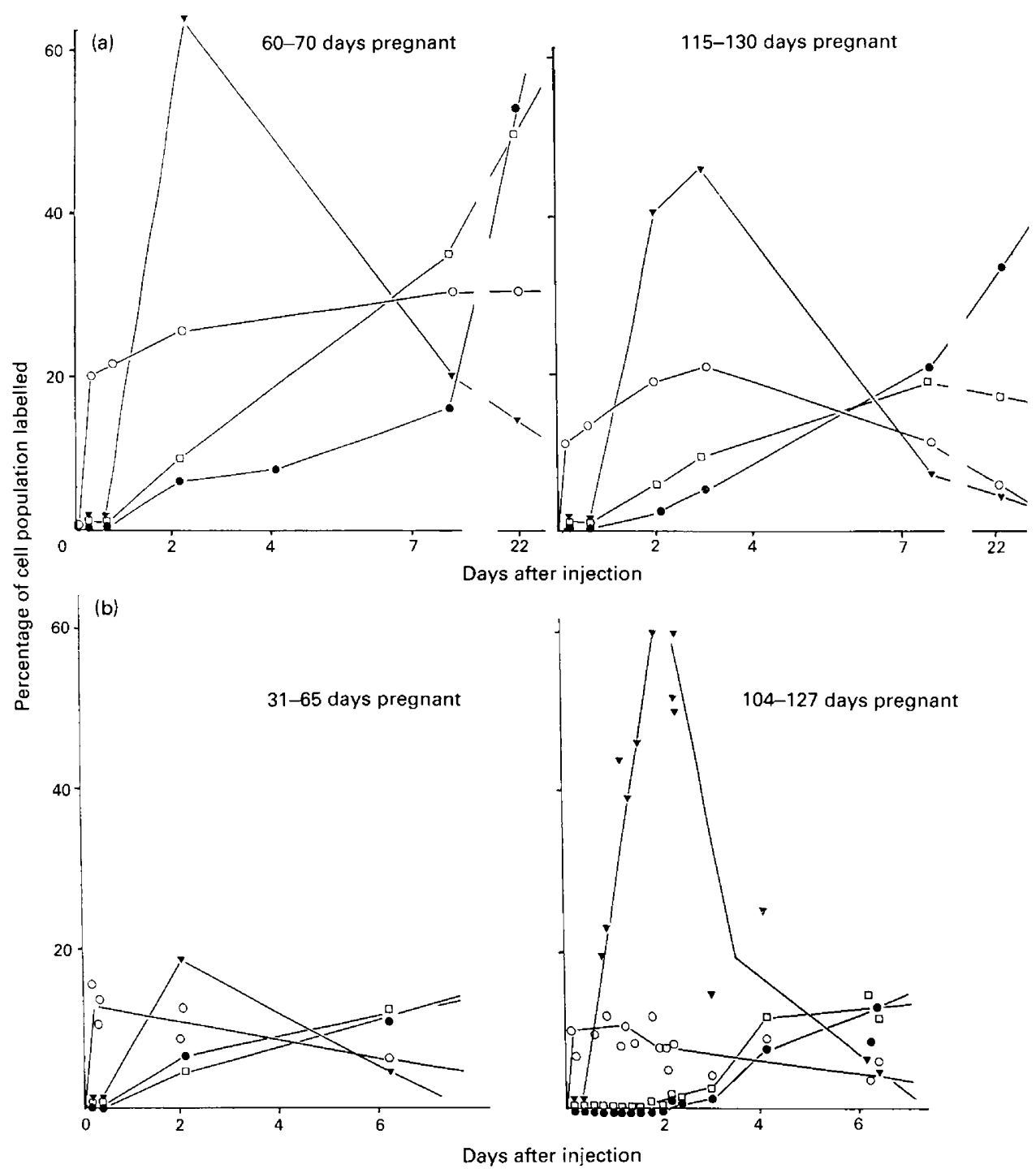

Fig. 5. Time course of tritiated thymidine labelling of nuclei in (a) the sheep and (b) the goat placenta. The sequence of trophectoderm uninucleate $(O)$ to trophectoderm mature binucleate $(\boldsymbol{\nabla})$ to standard syncytium $(\square)$ to pyknotic syncytium ( ) is similar at all stages of pregnancy tested. The absence of labelling in the syncytium before $40 \mathrm{~h}$ is clearly demonstrated by results from goats between days 104 and 127 of pregnancy.

\section{Discussion}

This time-course study of tritiated thymidine incorporation into sheep and goat placental nuclei clearly demonstrates that most of the nuclei of the syncytium are derived from migration of trophectoderm binucleate cells. This has been reported in outline (Wooding et al., 1981) and is supported by our earlier morphological, freeze fracture and immunocytochemical work (reviewed by Wooding, 1982; 1992).

The uniformity and extent of binucleate cell production and migration indicates a central role in ruminant placental development and function. The number of binucleate cells starts to decrease only in the last week of pregnancy. The incidence of migration is a constant $4-5 \%$ of the total trophectoderm and our results indicate that all the binucleate cells migrate to form syncytium. This should be sufficient to maintain growth of the syncytium since one per cent division is thought to be sufficient to maintain a proliferating columnar epithelium (Wright and Alison, 1984). The results indicate that the interval between DNA synthesis preceding the nuclear division which initiates a binucleate cell and the subsequent commitment of the fully mature (granulated) cell to migrate is a minimum of $36-48 \mathrm{~h}$ in sheep and goats. Furthermore, as no highly labelled mature granulated binucleate cells persist for longer than $72 \mathrm{~h}$ after injection, it is probable that all are programmed to migrate from the trophectoderm to form the fetomaternal syncytium 

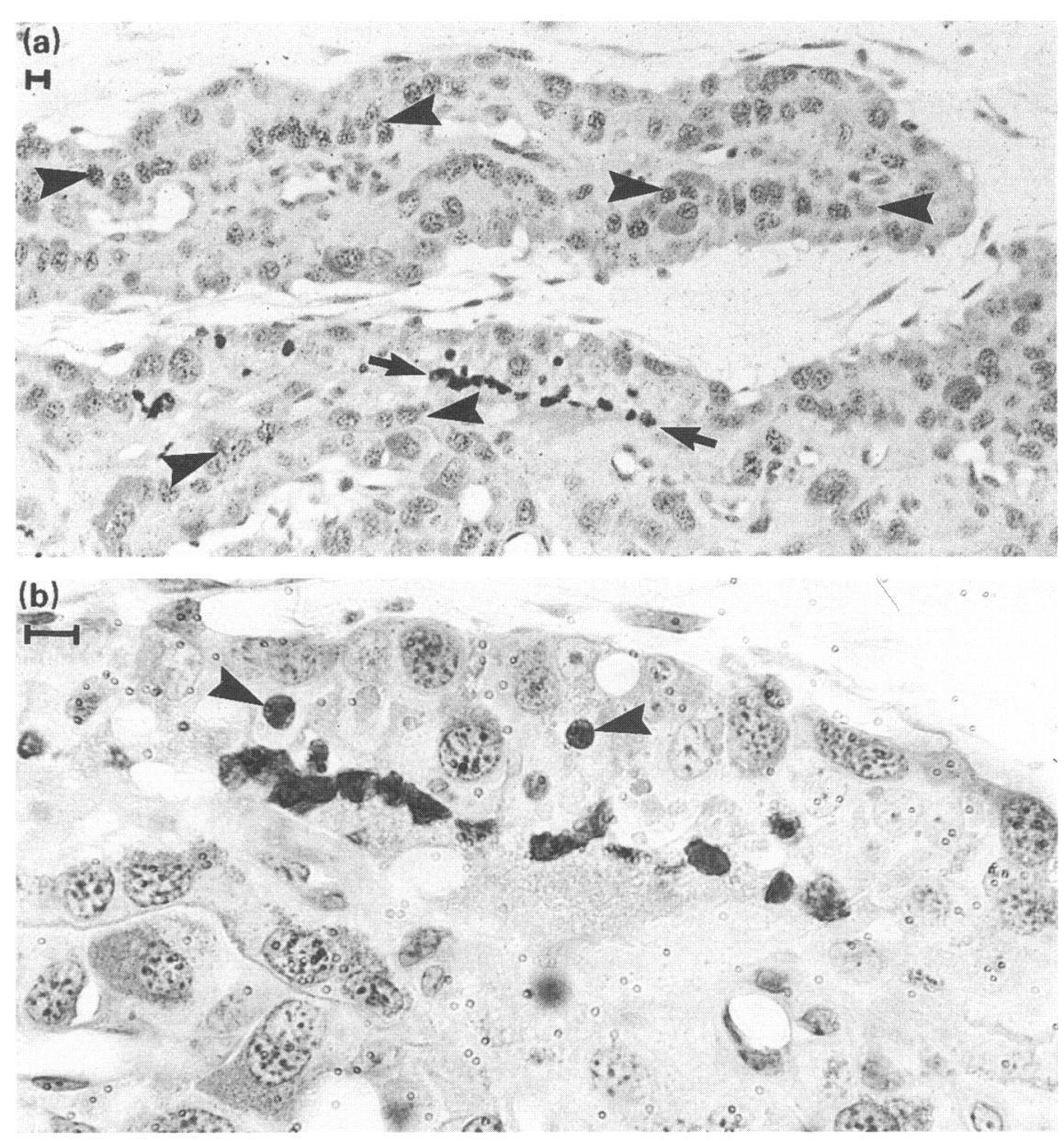

Fig. 6. (a) Light micrograph from a placentome of a day 75 pregnant goat shows the clear difference in appearance between the nuclei in the 'standard' syncytium (between arrowheads) and the 'pyknotic' syncytium (between arrows). (b) A higher magnification indicating phagocytotic uptake of two of the pyknotic fragments (arrowheads) by the trophectoderm. Scale bar $=10 \mu \mathrm{m}$.

throughout pregnancy. The cellular dynamics in these placentas are very similar between 50 and 90 , and 110-140 days post coitum. There is no consistent evidence for any change in the pattern of rapid and considerable binucleate cell and syncytium formation between the two periods. The delay in labelling of the nuclei in the syncytium is not due to lack of penetration of fetally infused $\left[{ }^{3} \mathrm{H}\right]$ thymidine, as occasional maternal connective tissue and endothelial cell nuclei are labelled $I \mathrm{~h}$ after injection into the fetus. Similarly, maternal infusion of tritiated thymidine labels fetal trophectodermal, connective tissue and endothelial cell nuclei after $4 \mathrm{~h}$ but not nuclei in the syncytium. Considering the difficulties of achieving equivalent thymidine dose rates of fetuses and equivalent injection sites in the fetus, the similarity of the results with sheep and goats must indicate a powerful and basic underlying process. Such a process is clearly incompatible with the earlier suggestions that all growth in a placentome finishes when it reaches its maximum weight at 90 days post coitum.

It is clear from Baur (1977) that the surface area of the fetomaternal exchange surface of many animals (including the cow placentomal placenta) increases continuously until very late in pregnancy. Since the fetomaternal exchange area determines fetal growth potential - all materials for fetal growth must cross it - Baur's results are not perhaps surprising and Stegemann (1974) has shown that fetal sheep weight at term is directly proportional to the fetomaternal surface area. Although Baur and Stegemann's morphometric methods are now known to be biased (Mayhew, 1991), they are perfectly valid for comparisons of general trends. The net increase in weight of sheep placentomes may cease by 90 days, but this must mask considerable further growth or differentiation of the fetomaternal exchange area within the placentome in the remaining 55 days, a period which includes the exponential phase of fetal growth. Stegemann's (1974) morphometric study showed that there was indeed an increase in fetomaternal surface area in sheep after 90 days post coitum but only up to 110-115 days post coitum. This would mean that in sheep the maximum maternofetal exchange area is reached uniquely early in gestation. This correlates with the observations that placentomal weight (Cloete, 1939; Alexander, 1964a,b), DNA concentration (Kulhanek et al., 1974) and number of placental nuclei (Teasdale, 1976) also reach their maxima by 90 days post coitum.

These results must be reconciled with continuing changes in functional indices: physiological parameters such as transport of urea (Kulhanek et al., 1974) and glucose and oxygen clearance 

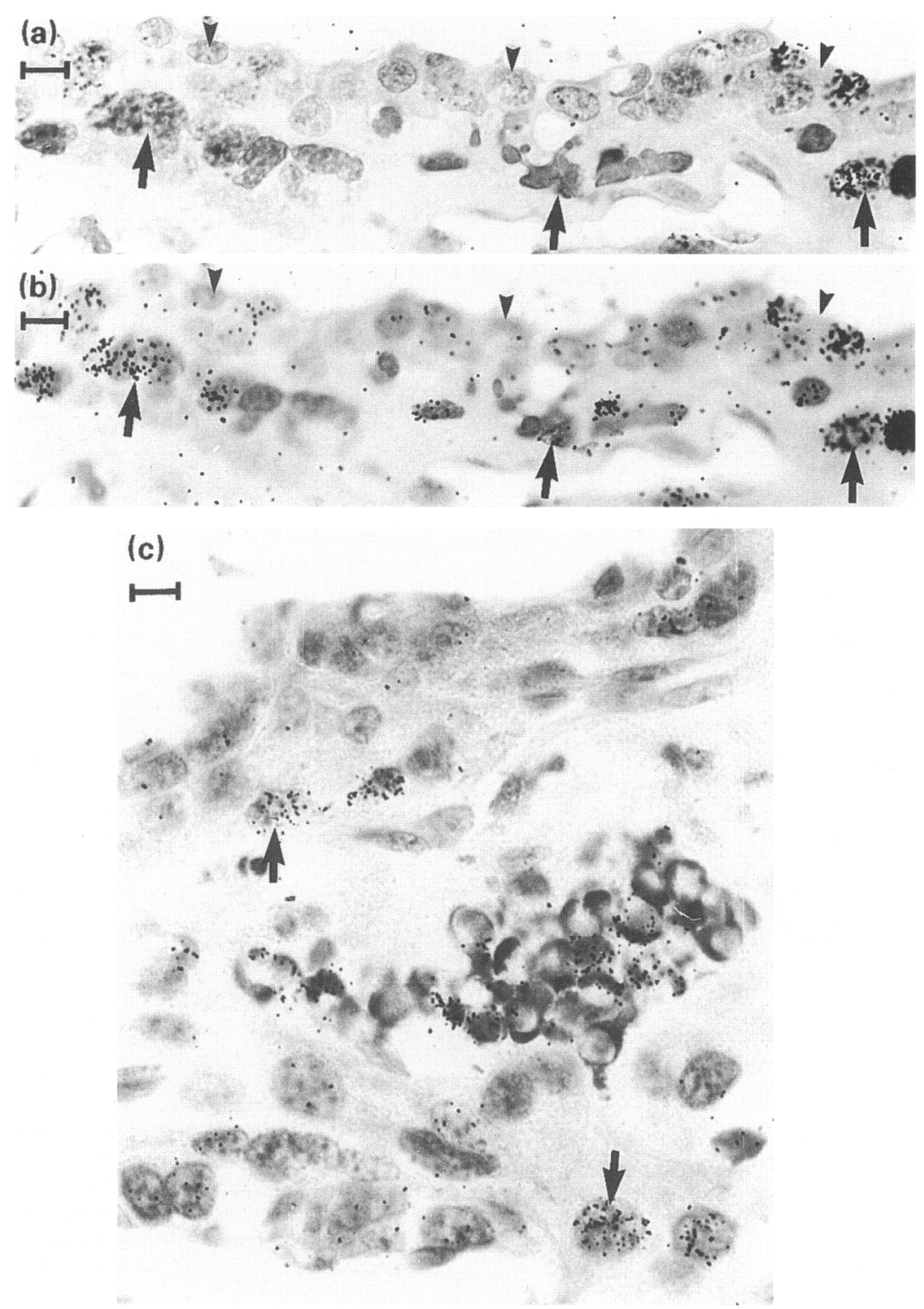

Fig. 7. Light microscope autoradiograph of sections of placentome from (a, b) day 72 and (c) day 127 pregnant goats sampled 7 days after tritiated thymidine was injected into the fetus. In (a) and (b) the section is photographed at two levels, (a) to demonstrate the nuclei and (b) the label. Some of both the pyknotic and standard nuclei are clearly labelled. Trophectoderm is indicated by the arrowheads, syncytium by arrows. In (c), a cluster of pyknotic nuclei in the syncytium show label equivalent to that in the adjacent standard syncytium (arrows). Scale bars $=10 \mu \mathrm{m}$.

(Bell, 1984), show fivefold, threefold and twofold linear increases, respectively, in the period 90-145 days post coitum. Stegemann (1974) suggested that this functional change is partly accommodated by a fourfold increase in the frequency and size of the fetal blood capillaries which was demonstrated morphometrically. This correlated well with the increase in endothelial nuclei in fetal cotyledons over the same period (Teasdale, 1976), although the total number of nuclei per unit volume of placenta did not alter.

A second structural change cited by Stegemann in the 90-145 days post coitum was the indentation of the fetal blood vessels into the trophectoderm bringing the two circulations closer together. Our results demonstrate that the trophectoderm is active up to term both in binucleate cell production and in their migration to form syncytium. This cellular activity would accommodate the considerable remodelling necessary for indentation, but migration cannot be a prerequisite for indentation since this characteristic is well developed in the unicellular trophectoderm of pigs, which has no binucleate or migratory cells (Steven, 1975). In sheep and goats, if DNA content and nuclear number remain constant in the face of ongoing DNA synthesis and binucleate cell formation as shown here, there must be an equivalent nuclear degradation. Our autoradiographic results provide a possible explanation and location for this degradation 

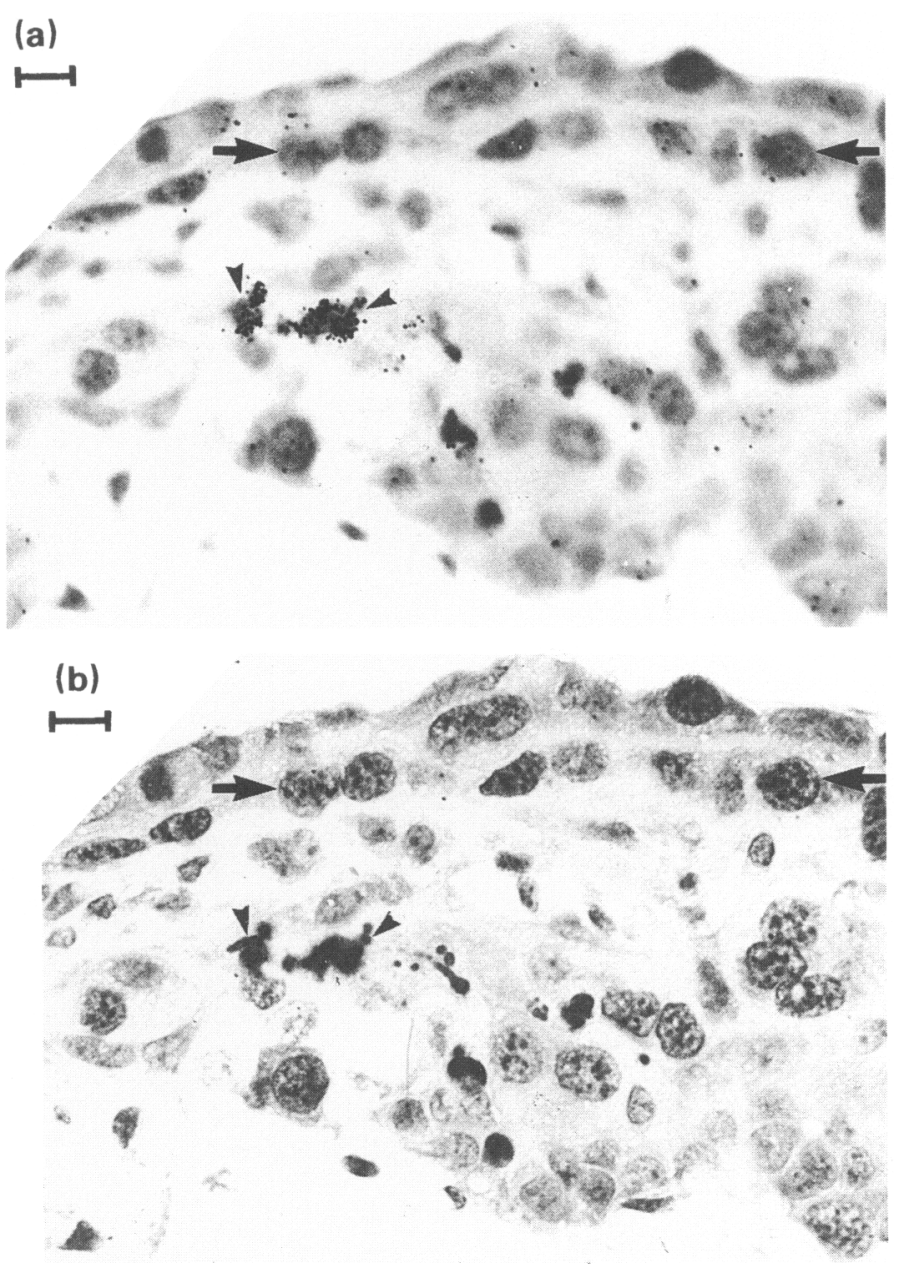

Fig. 8. Light microscope autoradiograph of a section of a placentome rom a day 72 pregnant goat sampled 7 days after tritiated thymidine was injected into the fetus. The section is photographed at two levels, (a) to demonstrate the nuclei and (b) the label. The pyknotic nuclei (arrowheads) are much more heavily labelled than those in the standard syncytium (between arrows). Scale bars $=10 \mu \mathrm{m}$.

in the standard to pyknotic transition seen in the syncytial plaque nuclei. We have ultrastructural evidence for trophectodermal phagocytosis of such pyknotic syncytium and this has also been suggested to occur in intercotyledonary regions during early placental growth in goats (Dent, 1973) and immediately after implantation in cows (Wathes and Wooding, 1980). This apparent need for continuous renewal may explain why this unique fetomaternal tissue is formed from small syncytial plaques rather than a continuous syncytium, since smaller units are more easily replaced. There is no evidence for any massive immunological attack on the syncytium by maternal lymphocytes as in the eventual elimination of the trophectodermal cup cells from the equine maternal endometrium (Allen, 1982). The maternofetal hybrid composition of the plaques may provide an effective immunological camouflage initially, but the cause and inevitability of death of the syncytial plaque during pregnancy remains to be established. Compared with a cellular epithelium, a further advantage of the syncytial plaques is their plasticity. Their transport capacity would be considerably enhanced by the continuous attenuation and very complex remodelling which increases the surface area presented ever closer to the maternal blood vessels. Both processes continue to term.

In summary, our results show that although others have shown no change in the size, weight, DNA content or the total number of nuclei in sheep placentomes between 90 and 145 days post coitum, increase in fetal vascularization and the evolution of a binucleate cell-syncytial plaque system appears to provide an efficient method of accommodating the necessary increase in transport systems required for a successful pregnancy. In ewes (and possibly in goats) the maternofetal exchange area apparently does not need to increase to term and provides another example of the remarkable variety of structural mechanisms evolved for placental exchange within the basic chorioallantoic system.

The authors thank B. Currie, I. Forsyth and C. Wathes for critical review of the manuscript, and J. Brown for her secretarial skills.

\section{References}

Alexander G (1964a) Studies on the placenta of the sheep (Ovis aries L). Placental size Joumal of Reproduction and Fertility 7 289-305

Alexander G (1964b) Studies on the placenta of the sheep (Ovis aries L). Effect of surgical reduction in the number of caruncles Joumal of Reproduction and Fertility 7 307-322

Allen WR (1982) Immunological aspects of the endometrial cup reaction and the effect of xenogeneic pregnancy in horses and donkeys Journal of Reproduction and Fertility Supplement 31 57-94

Baur R (1977) Morphometry of the placental exchange area Anatomy Embryology and Cell Biology 53 1-63

Bell AW (1984) Factors controlling placental and fetal growth and their effects on future production. In Reproduction in Sheep, pp 144-152 Ed. DH Lindsay and DT Pearce. Cambridge University Press, Cambridge

Cloete JHL (1939) Prenatal growth in the Merino sheep Onderstepoort Journal of Veterinary Science 13 418-552

Dent J (1973) Ultrastructural changes in the intercotyledonary placenta of the goat during early pregnancy Joumal of Anatomy 114 245-259

Kulhanek JF, Meschia G, Makowski EL and Battaglia FC (1974) Changes in DNA content and urea permeability of the sheep placenta American Joumal of Physiology 226 1257-1263

Mayhew TM(1991) The new stereological methods for interpreting functional morphology from slices of cells and organs Experimental Physiology 76 639-665

Stegemann JHJ (1974) Placental development in the sheep and its relation to fetal development. A qualitative and quantitative anatomic and histologic study Bijdragen tot de Dierkunde (Contributions to Zoology) 44 3-72

Steven DH (1975) Anatomy of the placental barrier. In Comparative Placentation, pp 25-57 Ed. DH Steven. Academic Press, London

Teasdale F (1976) Numerical density of nuclei in the sheep placenta Anatomical Record 185 187-196

Wallace LR (1948) The growth of lambs before and after birth in relation to the level of nutrition. Part II Journal of Agricultural Science 38 243-302

Wathes DC and Wooding FBP (1980) An electron microscopic study of implantation in the cow American Journal of Anatomy 159 285-306

Wooding FBP (1980) Electron microscopic localisation of binucleate cells in the sheep placenta using phosphotungstic acid Biology of Reproduction 22 357-365

Wooding FBP (1982) The role of the binucleate cells in ruminant placental structure Joumal of Reproduction and Fertility Supplement 31 31-39

Wooding FBP (1983) Frequency and localisation of binucleate cells in the placentomes of ruminants Placenta 4 527-540

Wooding FBP (1992) The synepitheliochorial placenta of ruminants. Binucleate cell fusions and hormone production Placenta 13 101-113

Wooding FBP, Flint APF, Heap RB and Hobbs T (1981) Autoradiographic evidence for migration and fusion of cells in the sheep placenta: resolution of a problem in placental classification Cell Biology International Reports 5 821-827

Wooding FBP, Flint APF, Heap RD, Morgan G, Buttle HL and Young IR (1986) Control of binucleate cell migration in the placenta of ruminants Journal of Reproduction and Fertility 76 499-512

Wright $N$ and Alison M (1984) The Biology of Cell Populations. Oxford University Press, Oxford 